\title{
Structural annotation of electro- and photochemically generated transformation products of moxidectin using high-resolution mass spectrometry
}

\author{
Lisa Kotthoff \\ BAM, Germany \\ Sarah-Louise O'Callaghan \\ Technological University Dublin, C16445386@mytudublin.ie \\ Jan Lisec \\ BAM, Germany
}

See next page for additional authors

Follow this and additional works at: https://arrow.tudublin.ie/scschcpsart

Part of the Analytical Chemistry Commons

\footnotetext{
Recommended Citation

Kotthoff L, O'Callaghan SL, Lisec J, Schwerdtle T, Koch M. Structural annotation of electro- and photochemically generated transformation products of moxidectin using high-resolution mass spectrometry. Anal Bioanal Chem. 2020 May;412(13):3141-3152. doi: 10.1007/s00216-020-02572-1. Epub 2020 Mar 14. PMID: 32172328.
}

This Article is brought to you for free and open access by the School of Chemical and Pharmaceutical Sciences at ARROW@TU Dublin. It has been accepted for inclusion in Articles by an authorized administrator of ARROW@TU Dublin. For more information, please contact arrow.admin@tudublin.ie, aisling.coyne@tudublin.ie, gerard.connolly@tudublin.ie.

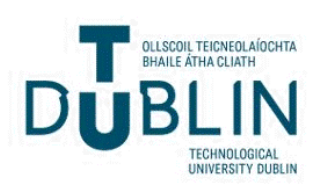


Authors

Lisa Kotthoff, Sarah-Louise O'Callaghan, Jan Lisec, Tanja Schwerdtle, and Matthias Koch

This article is available at ARROW@TU Dublin: https://arrow.tudublin.ie/scschcpsart/110 


\title{
Structural annotation of electro- and photochemically generated transformation products of moxidectin using high-resolution mass spectrometry
}

\author{
Lisa Kotthoff ${ }^{1} \cdot$ Sarah-Louise O'Callaghan ${ }^{2} \cdot$ Jan Lisec $^{1} \cdot$ Tanja Schwerdtle $^{3} \cdot$ Matthias Koch $^{1}$ \\ Received: 18 December 2019 /Revised: 20 February 2020 / Accepted: 2 March 2020 / Published online: 14 March 2020 \\ (C) Springer-Verlag GmbH Germany, part of Springer Nature 2020
}

\begin{abstract}
Moxidectin (MOX) is a widely used anthelmintic drug for the treatment of internal and external parasites in food-producing and companion animals. Transformation products (TPs) of MOX, formed through metabolic degradation or acid hydrolysis, may pose a potential environmental risk, but only few were identified so far. In this study, we therefore systematically characterized electro- and photochemically generated MOX TPs using high-resolution mass spectrometry (HRMS). Oxidative electrochemical (EC) TPs were generated in an electrochemical reactor and photochemical (PC) TPs by irradiation with UV-C light. Subsequent HRMS measurements were performed to identify accurate masses and deduce occurring modification reactions of derived TPs in a suspected target analysis. In total, 26 EC TPs and 59 PC TPs were found. The main modification reactions were hydroxylation, (de-)hydration, and derivative formation with methanol for EC experiments and isomeric changes, (de-)hydration, and changes at the methoxime moiety for PC experiments. In addition, several combinations of different modification reactions were identified. For 17 TPs, we could predict chemical structures through interpretation of acquired MS/MS data. Most modifications could be linked to two specific regions of MOX. Some previously described metabolic reactions like hydroxylation or O-demethylation were confirmed in our EC and PC experiments as reaction type, but the corresponding TPs were not identical to known metabolites or degradation products. The obtained knowledge regarding novel TPs and reactions will aid to elucidate the degradation pathway of MOX which is currently unknown.
\end{abstract}

Keywords Veterinary drug $\cdot$ Moxidectin $\cdot$ Transformation products $\cdot$ Electrochemistry $\cdot$ Photochemistry $\cdot$ LC/HRMS

\section{Introduction}

Electronic supplementary material The online version of this article (https://doi.org/10.1007/s00216-020-02572-1) contains supplementary material, which is available to authorized users.

Matthias Koch

Matthias.koch@bam.de

1 Department of Analytical Chemistry and Reference Materials, Bundesanstalt für Materialforschung und -prüfung (BAM), Richard-Willstätter-Straße 11, 12489 Berlin, Germany

2 School of Chemical and Pharmaceutical Sciences, Technological University Dublin (TU Dublin), Kevin Street, Dublin 8, Ireland

3 Institute of Nutritional Science, University of Potsdam, Arthur-Scheunert-Allee 114-116, 14558 Nuthetal, Potsdam, Germany
The veterinary drug moxidectin (MOX) belongs to the milbemycin subfamily of macrocyclic lactones $[1,2]$. The broad-spectrum antiparasitic agent is widely used to treat and prevent endo- and ecto-parasitic infections like roundworms, fluke, and lice. Food-producing animals like cattle, sheep, goats, and pigs as well as companion animals like cats and dogs are medicated with MOX. Several metabolic studies of MOX in various animals have been published so far, concluding in general that MOX is only moderately metabolized [3-8]. The fecal excretion percentage of unaltered MOX is reported between 44 and 77\% [9] and residues of MOX can be detected in feces up to 42 days after treatment [10]. In 2017, the EMA (European Medicines Agency) rated MOX as a persistent, bioaccumulative, and toxic (PBT) substance and concluded that its common usage constitutes potential environmental risks [11]. Consequently, the environmental fate of 
MOX has been characterized by the FDA (Food and Drug Administration) [12], providing evidence that MOX shows a high adsorption to soil (logKoc 4.27-4.62) [12] and moderate water solubility (logKow 4.77) [12]. Rapid environmental degradation of MOX is obtained by photolysis (half-life in water $6.8 \mathrm{~h}$ ), while biodegradation in soils occurs at a moderate speed (half-life 2 months).

The structure of MOX (Fig. 1) is based on a 16-membered macrocyclic ring fused with a benzofuran and a spiroketal function. The spiroketal contains a methoxy moiety at $\mathrm{C} 23$ and a branched olefinic group at $\mathrm{C} 25[1,2]$.

Two metabolic modifications of MOX have been described previously: hydroxylation reaction at the olefin-containing side chain (C25) or at the methyl groups of $\mathrm{C} 24$ or $\mathrm{C} 14$ [3-8] and an O-demethylation or the loss of the methoxime group [5]. Studies suggest that MOX is a rather stable compound. It was found that in cattle only $13 \%$ of MOX was converted into metabolites [2]. The FDA report mentioned at least 10 degradation products occurring in trace levels, without identification [12]. Awasthi et al. [13] investigated degradation experiments using thermal, base, and acid hydrolysis or oxidation with hydrogen peroxide and obtained two degradation products which were characterized as 3,4-epoxymoxidectin and 23-keto-nemadectin. In general, metabolites (formed by biotransformation processes in living organism) and degradation products (formed by various microbial, biotic, and abiotic environmental processes) can be summarized as transformation products (TPs) [14]. Knowledge regarding TPs is important, because they are potentially more harmful, more toxic, or more persistent compared with their precursor

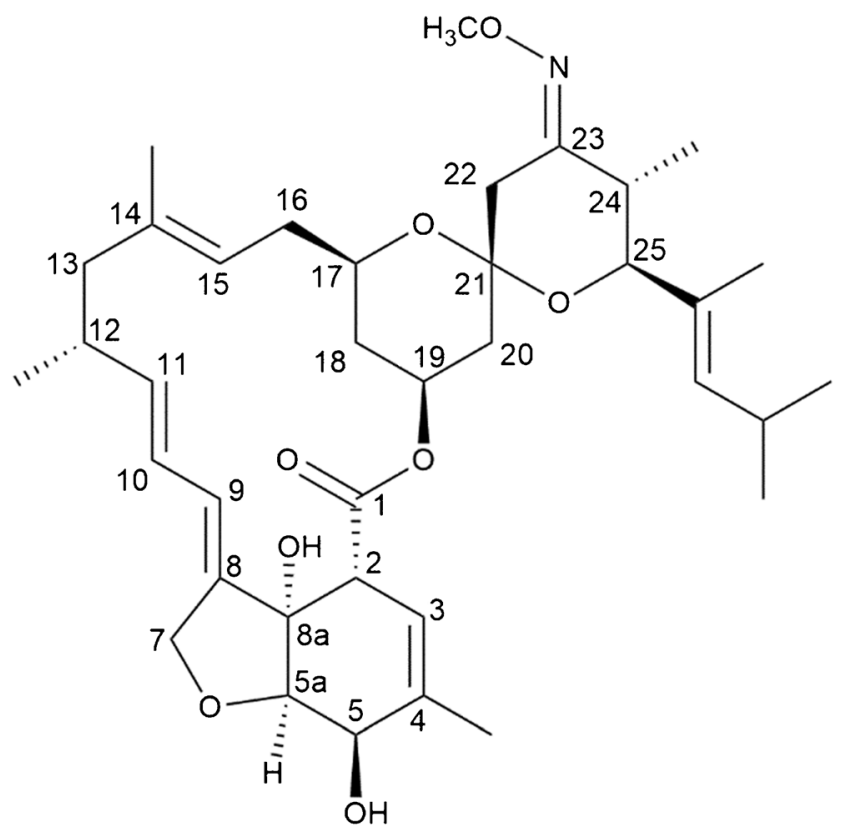

Fig. 1 Chemical structure of moxidectin (MOX)
$[15,16]$. TPs of veterinary drugs are possible residues in foodstuff or in environmental matrices [14, 17], but frequently occur only at low levels (up to trace levels for MOX) in animal and environmental samples [17, 18], rendering the identification of novel TPs by non-targeted liquid chromatography/ high-resolution mass spectrometry (LC/HRMS) often difficult $[19,20]$. The process to generate transformation products in a laboratory environment is termed as simulation. For simulation and identification of novel TPs, different laboratory approaches are used [21], which simulate different chemical mechanisms like redox or radical-based reactions. Simple redox reactions can be induced by applying a potential in the cell of an electrochemical reactor. Furthermore, oxidation reactions can be simulated by chemically oxidizing agents or Fenton(-like) reactions. The Fenton reaction generates hydroxyl radicals, which initiate the oxidation process. Photochemically induced oxidation reactions simulate naturally occurring radical reactions by irradiation with light. For simulation of drug TPs, a widely used instrumental method is based on the combination of electrochemistry with mass spectrometry (EC/MS) [22-24]. The online coupling between EC cell and MS enables the detection of stable TPs and also transient species. A broad reaction spectrum can be simulated by electrochemistry [25], inducing oxidation or reduction reactions dependent on the chosen potential polarity. The absence of complex matrices in such experiments simplifies TP identification. Several studies showed that electrochemistry can simulate cytochrome $\mathrm{P} 450$-mediated metabolic reactions of drug metabolism, which are mostly simple redox reactions $[23,26]$. In contrast, naturally occurring radical reactions can be simulated using a photochemical (PC) approach.

The lab-scale simulation of $\mathrm{PC}$ processes is performed by irradiation with light of a certain wavelength for a defined time [27]. Due to the absorption of light by functional groups, transformation processes are initiated and TPs are formed. Photochemical irradiation experiments are used to simulate the environmental degradation by sunlight., To induce more possible transformation reactions, light of a defined range of wavelength and high energy, like UV-C light (200-280 nm), is used in lab simulations.

The aim of this study was to generate, for the first time, TPs of MOX by electro- and photochemistry in order to simulate different natural processes such as redox and radical-based reactions. The focus was placed on the annotation of primarily new MOX TPs through chromatographic separation and interpretation of their mass spectra (LC-HRMS). Molecular formulas of the TPs, derived from accurate mass determination, contain information about occurring modification reactions. Structure prediction was obtained by investigating the MS/ MS fragmentation pattern. The newly found EC and PC TPs are compared with each other and with MOX metabolites or degradation products known from literature. Our study results 
will contribute to understand the still unknown degradation pathway of MOX.

\section{Material and methods}

Chemicals Moxidectin (purity 95.3\%, Pharmaceutical Secondary Standard) was purchased from Sigma-Aldrich (Steinheim, Germany). Acetonitrile and methanol were purchased from Chemsolute (Renningen, Germany). Ammonium acetate was purchased from J.T. Baker (Deventer, The Netherlands) and formic acid from Merck (Darmstadt, Germany). Ultrapure water was produced by a Purelab Flex 2 system, ELGA Veolia Water Technologies (Celle, Germany). All standard chemicals were of p.a. grade and all solvents (acetonitrile, methanol) of LC/MS grade.

Electrochemistry/mass spectrometry The ROXYTM system (Antec Scientific, Zoeterwoude, The Netherlands) was used for electrochemical oxidation consisting of a potentiostat and an electrochemical flow-through cell ( $\mu$ PrepCell, Antec Leyden, Zoeterwoude, Netherlands). The potentiostat was fully operated using the Dialogue Elite ${ }^{\mathrm{TM}}$ software (Antec Leyden, Zoeterwoude, The Netherlands) version 2.0.0.81. Mass voltammograms were recorded by coupling of the electrochemical cell to an electrospray ionization source of a TripleTOF® 6600 Quadrupole Time-of-Flight (QTOF) mass analyzer (Sciex, Darmstadt, Germany). Data was acquired using Analyst ${ }^{\circledR}$ TF1.8.0 including data processing. For further data processing, in-house scripts using the statistical working environment R (REF) [28] were applied. The software Origin 2019 (OriginLab, Northampton, MA, USA) was used for the graphical representation of the three-dimensional mass voltammograms. MOX was dissolved in acetonitrile and further diluted with a solvent mixture consisting of methanol:acetonitrile:water $(1: 1: 1$; $\mathrm{v} / \mathrm{v} / \mathrm{v}$ ) with $1 \%$ formic acid to a final concentration of $30 \mu \mathrm{M}$. The MOX-solvent mixture was pumped through the EC cell by a Legato ${ }^{\circledR} 110$ dual rate system syringe pump (KD Scientific, Hollison, MA USA) with a flow rate of $10 \mu \mathrm{L} / \mathrm{min}$. The EC cell, a three-electrode arrangement, was equipped with an auxiliary electrode (fully inert polymeric material containing conductive carbon), a HyREFTM reference electrode $\left(\mathrm{Pd} / \mathrm{H}_{2}\right)$, and a borondoped diamond (BDD) working electrode. The working electrode and auxiliary electrode were separated by two $100-\mu \mathrm{m}$ spacers. The potential by the potentiostat was ramped between 0 and $3500 \mathrm{mV}$ with a scan rate of $10 \mathrm{mV} / \mathrm{s}$ (continuous scan mode). The working electrode was activated by a manufacturer-provided pulse cleaning program (potential $\mathrm{E} 1,+2 \mathrm{~V}$; potential $\mathrm{E} 2,-2 \mathrm{~V}$; potential E3, $0 \mathrm{~V}$; time $\mathrm{t} 1,1000 \mathrm{~ms}$; time $\mathrm{t} 2,1000 \mathrm{~ms}$; time $\mathrm{t} 3$, $0 \mathrm{~ms}$; continuously change for $5 \mathrm{~min}$ ) before each measurement. The experimental parameters for MS detection are listed in Table 1. Each mass voltammogram was recorded at least three times to ensure reproducibility. Also control measurements with the solvent mixture without MOX were performed. In addition to the online EC/ HRMS measurements, aliquots were collected into a HPLC vial, and then, the mixture was used for further LC/HRMS measurements.

Photochemistry A water-cooled quartz laboratory UV reactor (photoLab batch-M mid volume 250-400 mL, Peschl Ultraviolet, Mainz, Germany) equipped with a $150-\mathrm{W}$ medium pressure mercury lamp (TQ 150, Heraeus Noblelight, Hanau, Germany) was used for all UV irradiation experiments to simulate UV-(C) light $(\lambda>200 \mathrm{~nm})$. The measured irradiance of the UV-(C) lamp was $140 \mathrm{~W} / \mathrm{cm}^{2}$ (distance $8 \mathrm{~cm}$ ). For irradiation studies, $200 \mathrm{~mL}$ of a $100 \mu \mathrm{M}$ MOX solution (water:acetonitrile, 50:50, v/v) was placed in the reactor vessel and constantly stirred with a magnetic stirring device $\left(600 \mathrm{~min}^{-1}\right)$. The water-cooling system of the UV reactor was set to $10^{\circ} \mathrm{C}$. After temperature equilibration, the UV lamp was activated and samples $(1 \mathrm{~mL})$ were collected at $0,15,30$, 45, 60, 90, 180, and $240 \mathrm{~min}$. All samples were diluted 1:1 with acetonitrile for LC/HRMS analysis (can be omitted) and the samples were stored in a fridge $\left(4^{\circ} \mathrm{C}\right)$. The experiment was performed in triplicate.

Liquid chromatography/mass spectrometry LC/HRMS analysis of electrochemical and photolysis samples was performed with a Agilent 1290 Infinity II UHPLC (Agilent Technologies, Waldbronn, Germany) connected to an electrospray ionization source of a TripleTOF® 6600 Quadrupole Time-of-Flight (TTOF) mass analyzer (Sciex, Darmstadt, Germany). The UHPLC system consists of a 1290 Infinity II multisampler, a 1290 Infinity II flexible pump, and a 1290 Infinity II multicolumn thermostat. The analytical column was a Luna Omega PS

Table 1 Parameters of the ESI-TripleTOF® for the EC/HRMS measurements

$\begin{array}{ll}\text { Experimental parameters } & \\ \text { Gas temperature } & 250{ }^{\circ} \mathrm{C} \\ \text { Ion source gas 1 (nitrogen) } & 25 \mathrm{~L} / \mathrm{min} \\ \text { Ion source gas 2 (nitrogen) } & 25 \mathrm{~L} / \mathrm{min} \\ \text { Curtain gas (nitrogen) } & 25 \mathrm{~L} / \mathrm{min} \\ \text { Ion spray voltage floating } & 5500 \mathrm{~V} \\ \text { Mass range parameters } & \\ \text { Collision energy } & 10 \mathrm{~V} \\ \text { Declustering potential } & 80 \mathrm{~V} \\ \text { Mass range } & 100-800 \mathrm{Da}\end{array}$


C18, particle size $5 \mu \mathrm{m}$, pore size $100 \AA, 250 \times 4.6 \mathrm{~mm}$ (Phenomenex, Torrance, CA, USA) and the column oven was set to $40{ }^{\circ} \mathrm{C}$. For separation, a mobile phase of (A) acetonitrile and (B) $\mathrm{H}_{2} \mathrm{O}$ with $5 \mathrm{mM}$ ammonium acetate and $0.1 \%$ formic acid was used. A gradient program was used starting with $30 \%$ (A) for $1 \mathrm{~min}$. Within $10 \mathrm{~min}$, (A) was raised to $70 \%$. Then, over $15 \mathrm{~min}$, (A) was raised up to $95 \%$. After maintaining $95 \%$ A for $2 \mathrm{~min}$, it was decreased within $2 \mathrm{~min}$ to $30 \%$ (A), and then, the column was re-equilibrated for $10 \mathrm{~min}$. The flow rate of the mobile phase was $0.8 \mathrm{~mL} / \mathrm{min}$ and the injection volume was $5 \mu \mathrm{L}$. The conditions for the TTOF are listed in Table 2, an information-dependent acquisition (IDA) was included for MS/MS experiments. The LC/HRMS system was controlled via Analyst ${ }^{\circledR}$ TF1.8.0 (AB Sciex) and the data were processed by SciexOS and using inhouse scripts of the statistical working environment $\mathrm{R}$ [28].

The mass accuracy of the used Sciex TTOF is $<2 \mathrm{ppm}$ and was confirmed via a tuning run before any measurement. To assign a potential sum formula and chemical structure to a measured ion mass, all possible sum formulas within $3 \mathrm{ppm}$ deviation around the respective $m / z$ were calculated, allowing only the elements $\mathrm{C}, \mathrm{H}$, and $\mathrm{O}$, together with $\mathrm{N}$ and $\mathrm{Na}$, to account for adduct formation in the ESI ion source. If more than one structural proposal remained, a fit of the isotopomer distribution (sigma value) was used to rank candidates. Additionally, the modifications in relation to MOX were calculated divided into gain and loss of atoms. Then, the best suggestion was selected with focus on reasonable gain and loss groups. MS/MS spectra, which were acquired in IDA mode, allowed a further inference of structural confirmation of the precursor molecule.

Table 2 Parameters of the ESI-TripleTOF® for the LC/HRMS measurements, including MS/MS experiments

\begin{tabular}{ll} 
Experimental parameters & \\
Gas temperature & $350{ }^{\circ} \mathrm{C}$ \\
Ion source gas 1 (nitrogen) & $50 \mathrm{~L} / \mathrm{min}$ \\
Ion source gas 2 (nitrogen) & $45 \mathrm{~L} / \mathrm{min}$ \\
Curtain gas (nitrogen) & $45 \mathrm{~L} / \mathrm{min}$ \\
Ion spray voltage floating & $5500 \mathrm{~V}$ \\
Mass range parameters-MS 1 & \\
Collision energy & $10 \mathrm{~V}$ \\
Declustering potential & $80 \mathrm{~V}$ \\
Mass range & $100-800 \mathrm{Da}$ \\
Mass range parameters-MS 2 & \\
Collision energy & $40 \mathrm{~V}$ \\
Collision energy spread & $20 \mathrm{~V}$ \\
Declustering potential & $80 \mathrm{~V}$ \\
Mass range & $50-800 \mathrm{Da}$ \\
\hline
\end{tabular}

\section{Results and discussion}

\section{Electrochemical investigation}

\section{Online EC/HRMS}

The generation of MOX-derived EC TPs was done by an electrochemical reactor connected to HRMS. Molecular formulas were assigned to generated TPs based on accurate mass. The MOX-containing solution was transferred into the electrochemical cell where an electric potential was applied. The potential was ramped from 0 up to $+3.5 \mathrm{~V}$, thus inducing oxidation reactions. The generated TPs were directly analyzed by ESI-HRMS. The first step was to optimize the experimental conditions like solvent combinations, modifier, and working electrode materials. The highest number of generated TPs and best reproducibility were achieved by using the BDD working electrode and a solvent mixture consisting of methanol:acetonitrile:water $(1: 1: 1, \mathrm{v} / \mathrm{v} / \mathrm{v})$ with $1 \%$ formic acid.

In Fig. 2, a three-dimensional mass voltammogram of MOX is plotted, presenting the mass spectra against the applied potential ( 0 to $3.5 \mathrm{~V})$. The signal intensity of $\operatorname{MOX}(\mathrm{m} / \mathrm{z}$ 640.385) decreases with increasing potential. Simultaneously, and induced by rising potential, several $\mathrm{m} / \mathrm{z}$ traces show increasing intensity, indicating possible TPs, 18 of which are visualized. The maximum intensity is different, as well as the potential-dependent intensity course. In general, the TP formation started at a potential around $1 \mathrm{~V}$, exhibited intensity maxima between 1 and $2 \mathrm{~V}$, and decreased in intensity with further rising potential. For example, the most intense TP trace with $m / z 656$ showed a maximum around $1.5 \mathrm{~V}$ and a sharp intensity drop at $2 \mathrm{~V}$. Other TPs, for example, the TP trace with $m / z$ of 702 , do not drop in intensity after a maximum but exhibit rather a plateau. Some TP traces are only observable within a small potential range (i.e., $m / z 620$ or $m / z$ 729). Here the maximum intensity is reached, and then, the intensity is decreased to the initial value. The overall intensity decrease of the TP traces indicates that at higher potential values, above 2.5 V, MOX is not transformed to further TPs (there were also no TPs with lower $m / z$ occurring and the MOX signal intensity is stable). A possible reason for this behavior is that MOX and/or the TPs are going to be degraded by the high potential value into small fragments which were not detectable with MS. The higher the potential value is, the more energy is available for inducing reactions, so degradation is more likely.

\section{Offline EC/HRMS}

For further identification and structural proposals of the generated TPs, LC/HRMS measurements were made of an ECgenerated reaction mixture. The $\mathrm{EC}$ conditions were identical in relation to the online measurements; the MOX-containing 
Fig. 2 3D mass voltammogram of MOX. Mass traces $(\mathrm{m} / \mathrm{z})$ of the transformation products of MOX as $[\mathrm{M}+\mathrm{H}]^{+}$in dependence of the applied oxidation potential ramped from 0 to $3.5 \mathrm{~V}$

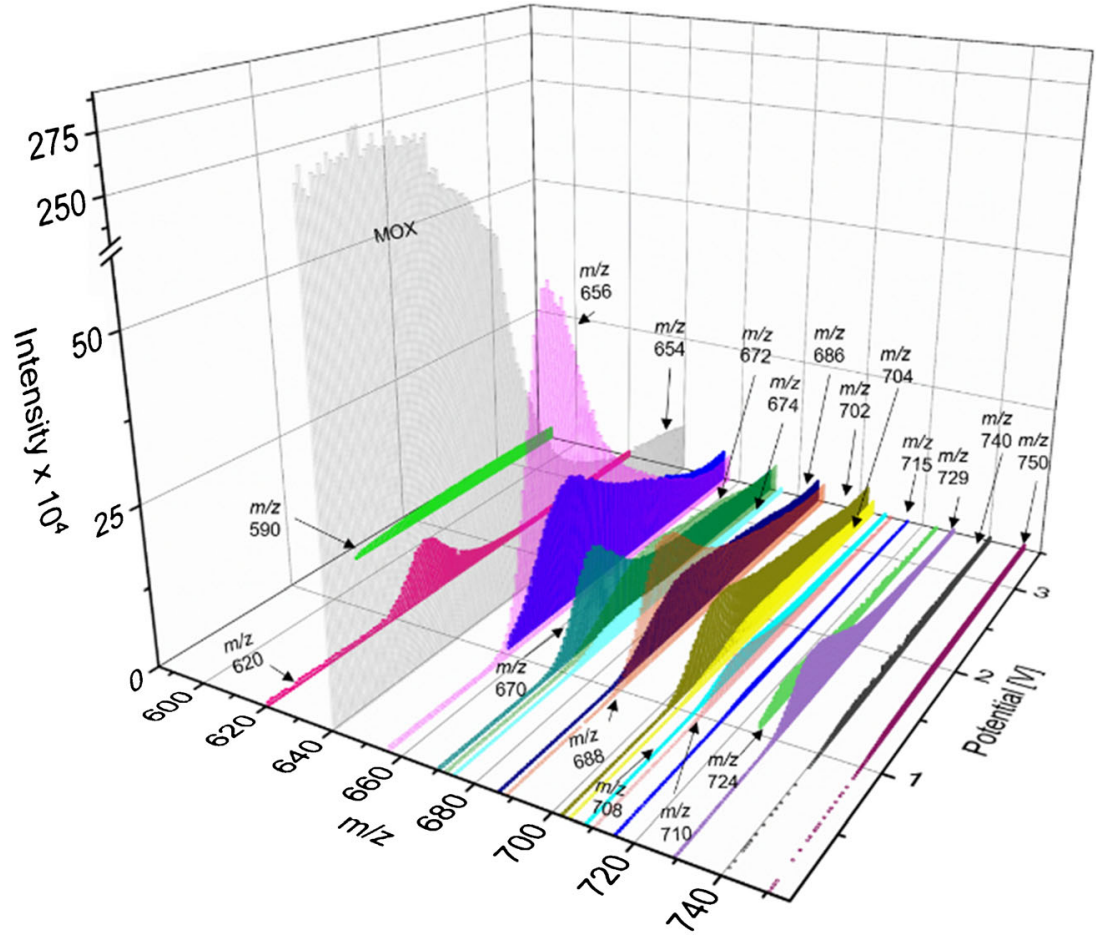

solution was collected in a vial connected to the effluent of the EC cell. The chromatogram (see Electronic Supplementary Material (ESM) Fig. S1) of the reaction mix showed many additional peaks (potential TPs) when compared with the MOX standard, but of low intensity in general. The 26 most intense TPs (EC1-EC26) were selected for further characterization and are listed in Table 3. Based on the measured accurate mass, sum formulas were calculated, allowing the deduction of the type of present MOX modifications. The evaluation of the different modification reactions yielded four major classes: (de-)hydrogenation, (de-)hydration, hydroxylation, and EC-induced derivative formation with solvents (mostly with methanol). Most EC TPs arise by addition of atoms (like oxygen) or small molecules (like water) to MOX. Only two EC TPs, EC21 and EC25, show a lower $\mathrm{m} / \mathrm{z}$ than MOX; both TPs show a dehydrogenation $(-\mathrm{H})$. The most common modification reaction is the hydroxylation $(+\mathrm{O})$, identified for $15 \mathrm{EC}$ TPs as either mono-hydroxylation (EC10, EC20), dihydroxylation (EC5), or tetra-hydroxylation (EC8). Also, combinations between hydroxylation and another modification reaction are present. Four EC TPs (EC1, EC6, EC7, EC9) show a hydration $\left(+\mathrm{H}_{2} \mathrm{O}\right)$ reaction, this reaction occurs always in combination with another modification reaction like hydroxylation (EC1 and EC6) or EC-induced derivatives with methanol (EC7 and EC9). The generation of solvent derivatives is observed for $13 \mathrm{EC} \mathrm{TPs,} \mathrm{where} \mathrm{in} 12$ cases methanol is added, and in one case formic acid (EC16). The derivative formation occurs mostly in combination with dehydrogenation. Often more than a single methanol derivative is visible; there are cases of generated di-methanol derivatives (EC19,
EC24) or combinations with other modification reactions (like hydroxylation). The generated solvent derivative TPs are mostly detected as sodium adducts. Each of the 26 observed TPs is characterized by a unique combination of measured $\mathrm{m} / \mathrm{z}$ and retention time. Similar $\mathrm{m} / \mathrm{z}$ observed at different retention time indicates isomeric TPs. Constitutional (structural) isomers as well as stereoisomers are possible. However, for EC TPs of MOX, structural isomers are more likely, because most chemical modifications may occur at different $\mathrm{C}$ atoms of MOX. EC offline measurements yielded two additional unique $\mathrm{m} / \mathrm{z}$ compared with $\mathrm{EC}$ online (in total 20 vs 18 ). These two peaks had been overlooked in online analysis because they were of low intensity and only $0.04 \mathrm{Da}$ apart from more abundant TPs (EC3/18, $\mathrm{m} / \mathrm{z} 654.364$ and EC26, $\mathrm{m} / \mathrm{z}$ 654.401). Separation by UPLC allowed the detection of these peaks. EC3/18 represent a dehydrogenation with hydroxylation while EC26 was generated by a dehydrogenation with methylation. Similar behavior is observed for EC4 $(\mathrm{m} / \mathrm{z}$ 670.359) and $\mathrm{EC} 23(\mathrm{~m} / \mathrm{z}, 670.395)$, where a dehydrogenation in combination with (a) di-hydroxylation (EC4) and (b) ECinduced derivatives with methanol (EC23) is identified. The structural elucidation is based on the evaluation of taken MS/ MS data; these are compared with the previously described ESI-MS fragmentation pathway of MOX (displayed in ESM Fig. S2). After considering the MS/MS data, the two smallest ESI fragments of MOX are most important for structural elucidation. These two fragments, fragment 1 and fragment 2 , are displayed in Fig. 3a.

Electrochemistry induced modifications occur within two regions of MOX. The first region comprises the nitrogen atom 
Table 3 HRMS data of 26 most intense EC-generated TPs (online and offline), listed as $[\mathrm{M}+\mathrm{H}]^{+}$ TPs, some TPs are detected as sodium or ammonium adducts. The intensity is calculated in relation to the occurring MOX signal (s > 15\%, m 3-15\%, w $1-3 \%$, vw $<1 \%)$

\begin{tabular}{|c|c|c|c|c|c|}
\hline Compound & $\begin{array}{l}\text { Retention time } \\
\text { (min) }\end{array}$ & calc. $m / z$ & $\begin{array}{l}\text { Molecular } \\
\text { formula }\end{array}$ & Suggested modification & Intensity \\
\hline MOX & 25.57 & 640.3849 & $\mathrm{C}_{37} \mathrm{H}_{54} \mathrm{NO}_{8}$ & & \\
\hline $\mathrm{EC} 1$ & 14.31 & 715.4146 & $\mathrm{C}_{37} \mathrm{H}_{60} \mathrm{~N}_{2} \mathrm{O}_{10} \mathrm{Na}$ & $+\mathrm{H}_{2} \mathrm{O},+\mathrm{O},+\mathrm{NH}_{4},+\mathrm{Na}$ & vw \\
\hline $\mathrm{EC} 2$ & 17.10 & 750.3698 & $\mathrm{C}_{39} \mathrm{H}_{55} \mathrm{~N}_{2} \mathrm{O}_{11} \mathrm{Na}$ & $+\mathrm{C}_{2} \mathrm{HNO}_{3},+\mathrm{Na}$ & $\mathrm{vw}$ \\
\hline EC3 & 18.54 & 654.3642 & $\mathrm{C}_{37} \mathrm{H}_{52} \mathrm{NO}_{9}$ & $-2 \mathrm{x} \mathrm{H},+\mathrm{O}$ & vw \\
\hline $\mathrm{EC} 4$ & 19.10 & 670.3586 & $\mathrm{C}_{37} \mathrm{H}_{52} \mathrm{NO}_{10}$ & $-\mathrm{H}_{2},+2 \times \mathrm{O}$ & $\mathrm{vw}$ \\
\hline EC5 & 19.49 & 672.3748 & $\mathrm{C}_{37} \mathrm{H}_{54} \mathrm{NO}_{10}$ & $+2 \mathrm{xO}$ & $\mathrm{vw}$ \\
\hline EC6 & 20.02 & 674.3899 & $\mathrm{C}_{37} \mathrm{H}_{56} \mathrm{NO}_{10}$ & $+\mathrm{H}_{2} \mathrm{O},+\mathrm{O}$ & $\mathrm{vw}$ \\
\hline EC7 & 21.02 & 729.4302 & $\mathrm{C}_{38} \mathrm{H}_{62} \mathrm{~N}_{2} \mathrm{O}_{10} \mathrm{Na}$ & $\begin{array}{l}-\mathrm{H},+\mathrm{H}_{2} \mathrm{O},+\mathrm{OCH}_{3},+\mathrm{NH}_{4}, \\
\quad+\mathrm{Na}\end{array}$ & vw \\
\hline EC8 & 21.19 & 704.3646 & $\mathrm{C}_{37} \mathrm{H}_{54} \mathrm{NO}_{12}$ & $+4 \mathrm{x} \mathrm{O}$ & $\mathrm{vW}$ \\
\hline EC9 & 21.40 & 729.4302 & $\mathrm{C}_{38} \mathrm{H}_{62} \mathrm{~N}_{2} \mathrm{O}_{10} \mathrm{Na}$ & $\begin{array}{l}-\mathrm{H},+\mathrm{H}_{2} \mathrm{O},+\mathrm{OCH}_{3},+\mathrm{NH}_{4}, \\
\quad+\mathrm{Na}\end{array}$ & $\mathrm{w}$ \\
\hline EC10 & 22.04 & 656.3799 & $\mathrm{C}_{37} \mathrm{H}_{54} \mathrm{NO}_{9}$ & $+\mathrm{O}$ & $\mathrm{s}$ \\
\hline EC11 & 22.23 & 708.3718 & $\mathrm{C}_{38} \mathrm{H}_{55} \mathrm{NO}_{10} \mathrm{Na}$ & $-\mathrm{H},+\mathrm{OCH}_{3},+\mathrm{Na}$ & vw \\
\hline $\mathrm{EC} 12$ & 22.33 & 688.4061 & $\mathrm{C}_{38} \mathrm{H}_{58} \mathrm{NO}_{10}$ & $+\mathrm{O},+\mathrm{OCH}_{3},+\mathrm{H}$ & $\mathrm{w}$ \\
\hline $\mathrm{EC} 13$ & 22.57 & 688.4061 & $\mathrm{C}_{38} \mathrm{H}_{58} \mathrm{NO}_{10}$ & $+\mathrm{O},+\mathrm{OCH}_{3},+\mathrm{H}$ & $\mathrm{w}$ \\
\hline $\mathrm{EC} 14$ & 23.14 & 688.4061 & $\mathrm{C}_{38} \mathrm{H}_{58} \mathrm{NO}_{10}$ & $+\mathrm{O},+\mathrm{OCH}_{3},+\mathrm{H}$ & $\mathrm{vw}$ \\
\hline $\mathrm{EC} 15$ & 23.20 & 686.3899 & $\mathrm{C}_{38} \mathrm{H}_{56} \mathrm{NO}_{10}$ & $-\mathrm{H},+\mathrm{OCH}_{3},+\mathrm{O}$ & vw \\
\hline EC16 & 23.24 & 740.3622 & $\mathrm{C}_{38} \mathrm{H}_{55} \mathrm{NO}_{12} \mathrm{Na}$ & $+2 \mathrm{x} \mathrm{O},+\mathrm{HCO}_{2},+\mathrm{Na}$ & $\mathrm{w}$ \\
\hline $\mathrm{EC} 17$ & 23.39 & 710.3880 & $\mathrm{C}_{38} \mathrm{H}_{57} \mathrm{NO}_{10} \mathrm{Na}$ & $-\mathrm{H},+\mathrm{O},+\mathrm{OCH}_{3},+\mathrm{Na}$ & $\mathrm{w}$ \\
\hline EC18 & 24.03 & 654.3642 & $\mathrm{C}_{37} \mathrm{H}_{52} \mathrm{NO}_{9}$ & $-2 \mathrm{x} \mathrm{H},+\mathrm{O}$ & $\mathrm{m}$ \\
\hline EC19 & 25.15 & 702.4217 & $\mathrm{C}_{39} \mathrm{H}_{60} \mathrm{NO}_{10}$ & $+2 \mathrm{xOCH}_{3}$ & $\mathrm{w}$ \\
\hline $\mathrm{EC} 20$ & 25.25 & 656.3798 & $\mathrm{C}_{37} \mathrm{H}_{54} \mathrm{NO}_{9}$ & $+\mathrm{O}$ & $\mathrm{w}$ \\
\hline $\mathrm{EC} 21$ & 25.50 & 620.3587 & $\mathrm{C}_{37} \mathrm{H}_{50} \mathrm{NO}_{7}$ & $-2 \mathrm{x} \mathrm{H},-\mathrm{H}_{2} \mathrm{O}$ & $\mathrm{m}$ \\
\hline $\mathrm{EC} 22$ & 26.29 & 724.4037 & $\mathrm{C}_{39} \mathrm{H}_{59} \mathrm{NO}_{10} \mathrm{Na}$ & $-2 \mathrm{x} \mathrm{H},+2 \mathrm{xOCH}_{3},+\mathrm{Na}$ & $\mathrm{m}$ \\
\hline $\mathrm{EC} 23$ & 26.42 & 670.3950 & $\mathrm{C}_{38} \mathrm{H}_{56} \mathrm{NO}_{9}$ & $-\mathrm{H},+\mathrm{OCH}_{3}$ & w \\
\hline EC24 & 26.54 & 702.4217 & $\mathrm{C}_{39} \mathrm{H}_{60} \mathrm{NO}_{10}$ & $+2 \mathrm{xOCH}_{3}$ & $\mathrm{w}$ \\
\hline $\mathrm{EC} 25$ & 27.16 & 590.3482 & $\mathrm{C}_{36} \mathrm{H}_{48} \mathrm{NO}_{6}$ & $-\mathrm{H},-\mathrm{H}_{2} \mathrm{O},-\mathrm{CH}_{3} \mathrm{O}$ & w \\
\hline EC26 & 27.33 & 654.4006 & $\mathrm{C}_{38} \mathrm{H}_{56} \mathrm{NO}_{8}$ & $-\mathrm{H},+\mathrm{CH}_{3}$ & $\mathrm{vw}$ \\
\hline
\end{tabular}

of the methoxime group (fragment 1, orange colored at Fig. $3 a)$. The second region comprises the double bonds present in fragment 2 and is visualized in green. Seven TPs (EC3, EC6, EC10, EC12, EC19, EC21, EC22) were selected for structural elucidation, based on their intensity and modification reaction. The associated MS/MS fragments to the fragmentation pathway are given in Tables S1-S3 (see ESM). The TP EC10 shows the highest signal intensity and has an accurate mass of $\mathrm{m} / \mathrm{z} 656.380$ which corresponds to a hydroxylation of MOX. The hydroxylation is identified at fragment 2 and this results in different possible structures, displayed in Fig. $3 \mathrm{~b}$. It can be assumed that the oxygen is added at a $\mathrm{C}$ atom of a double bond resulting in four possible positions, three at the conjugated double bonds $(\mathrm{C} 9, \mathrm{C} 10, \mathrm{C} 11)$ and one at the cyclohexene ring $(\mathrm{C} 3)$. After the hydroxylation enols are build first, but due to keto-enol tautomerism, it is supposed that the keto form is present. The TP EC20 has the same $m / z$ as EC10, but the retention time is different, indicating a different structure. However, the evaluation of the MS/MS data shows similar results, suggesting a hydroxylation at fragment 2 without further details. Most likely, these two TPs are constitutional isomers. The structural proposals of the selected ECvTPs are presented in Fig. 4. For all TPs, only one proposed structure is constructed; the additional opportunities described for the hydroxylated TPs in detail (Fig. 3b) are only marked. Next to EC10, most proposed structures of Fig. 4 show modifications at fragment 2 like EC3 (hydroxylation + dehydrogenation), EC6 (hydroxylation + hydration), EC12 (hydroxylation + EC-induced methanol derivative), and EC19 (di-methanol derivative). EC22 is also a generated derivative with two molecules of methanol, but one molecule of methanol is added at the nitrogen atom of fragment 1 , the other at fragment 2 . The proposed structure of EC21 is based on modifications at fragment 1 , the loss of water is placed at the spiroketal, and by dehydrogenation, a conjugated double-bond system is formed.

The obtained results show that several different TPs of MOX are formed by EC experiments applying positive 

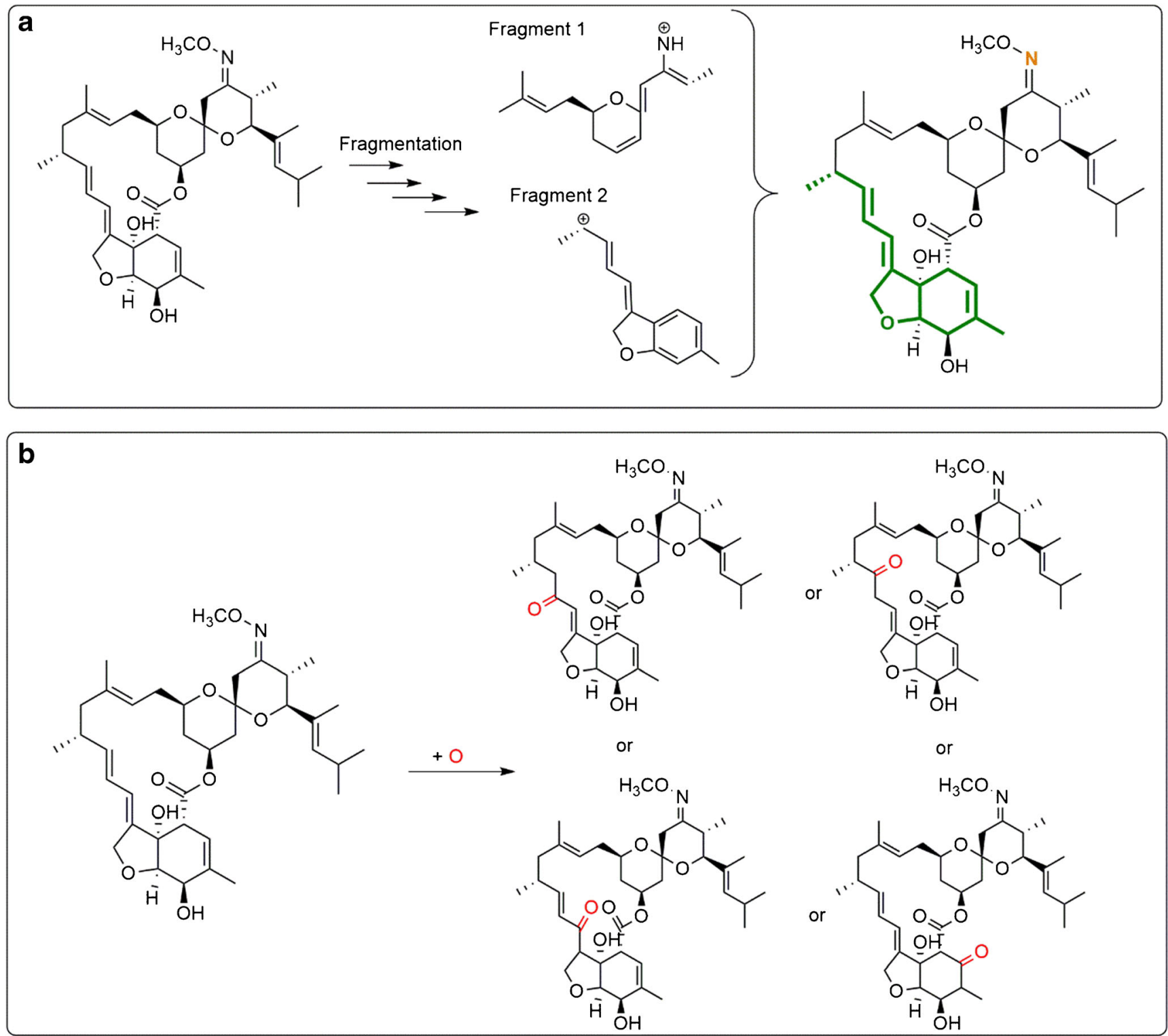

Fig. 3 a Two small known/used fragments of the ESI fragmentation (see ESM Fig. S2) of MOX are displayed and named as fragment 1 and fragment 2. Due to evaluation of MS/MS data of the TPs, two regions of MOX, based on fragment 1 and fragment 2, are identified, where the modifications are occurring. The regions are marked in orange (nitrogen atom) and green (fragment 2). b Example of EC10, the hydroxylation $(+\mathrm{O}$, red colour) of $\mathrm{MOX}$ is occurring at fragment 2 and four different $\mathrm{C}$ atoms $(\mathrm{C} 3, \mathrm{C} 9, \mathrm{C} 10, \mathrm{C} 11)$ are possible. All structural possibilities are displayed as keto form potentials. However, most TPs are only occurring with a low intensity, so the conversion rate is low. The found modification reactions and predicted structures indicate that MOX can be degraded and generate various TPs, whereby two regions are most reactive. This information can be helpful to determine the metabolic or degradation pathway of MOX.

\section{Photochemistry}

Kinetic studies on the photodegradation of MOX were reported by the FDA $[1,12]$, reporting a half-life value of $6.8 \mathrm{~h}$ in water. Several photodegradation products were found but remained unidentified. Here, we performed the photolysis of MOX, dissolved in water:acetonitrile (50:50), using an UV-C light reactor. Samples were taken at defined intervals within the whole process of $240 \mathrm{~min}$ and analyzed by LC-HRMS afterwards. Resulting chromatograms are shown in ESM Fig. S3.

At the beginning ( 0 min irradiation), only the MOX peak is present. After 15 min, several new peaks (PC TPs) can be detected. After longer irradiation times, the MOX peak is more and more decreased, and further PC TPs are occurring. 


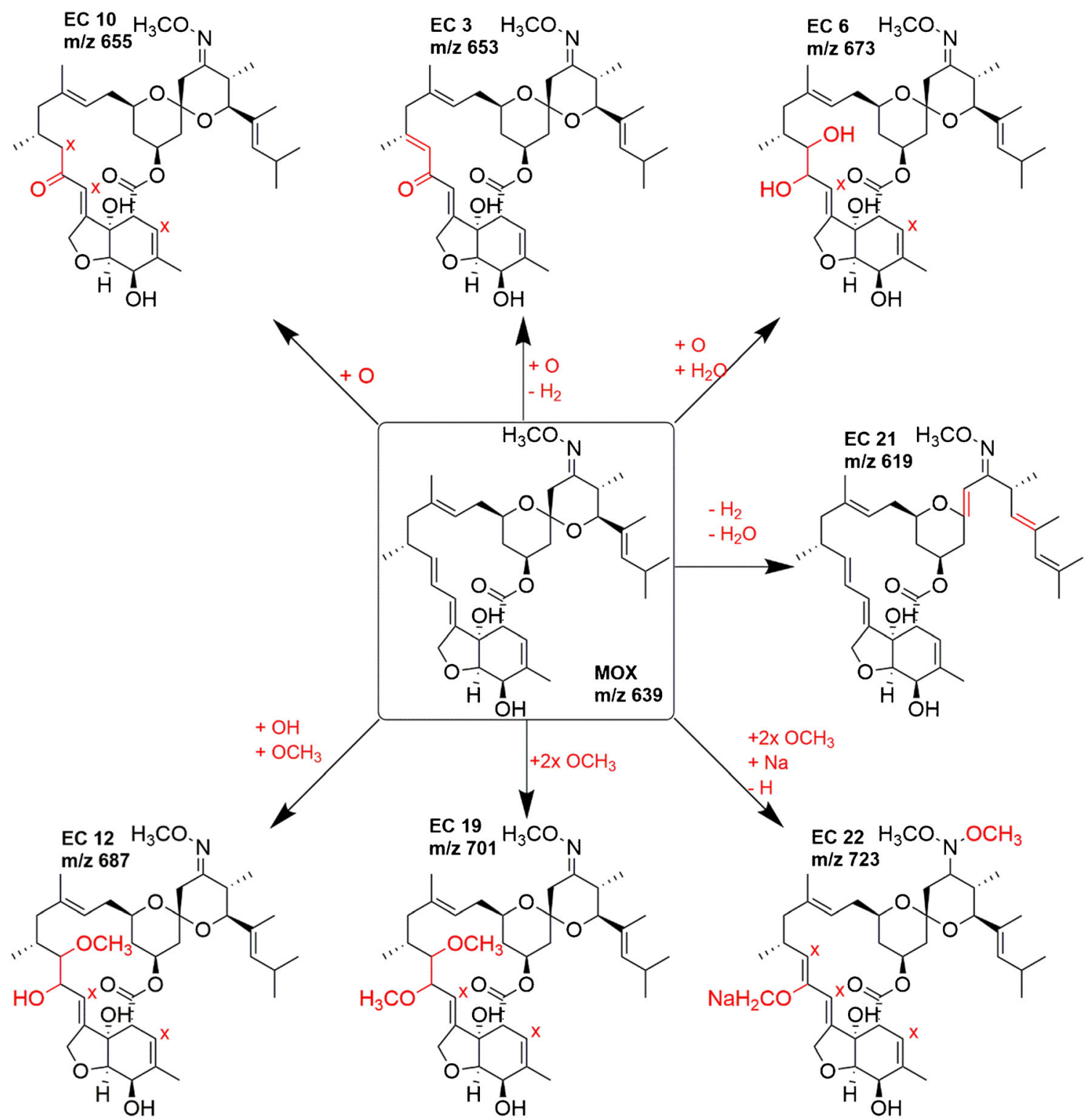

Fig. 4 Proposed structures of the TPs derived from EC experiments with MOX using BDD electrode. The x-position marks C atoms, where the modification (hydroxylation, hydration, or solvent derivates) can be instead of the shown version

In total, 59 PC TPs are found (ESM Table S4), whereby 19 unique $m / z$ are identified. Selected PC TPs, based on the different $\mathrm{m} / \mathrm{z}$, are listed in Table 4 .

In general, a huge variety of modification reactions is identified (see Table 4), but predominant modification reactions cannot be found. Most PC TPs (20, PC13-PC33) have a $\mathrm{m} / \mathrm{z}$ of 640.385 , identical to MOX. This means, by photolysis, a lot of isomers like stereoisomers (enantiomer or also diastereomer) are built. Also, hydration $\left(+\mathrm{H}_{2} \mathrm{O}\right)$ TPs (PC8-PC12) with $\mathrm{m} / \mathrm{z}$ of 658.395 and dehydration $\left(-\mathrm{H}_{2} \mathrm{O}\right)$ TPs (PC37-PC48) with $\mathrm{m} / \mathrm{z}$ of 622.374 are occurring frequently. Here, next to stereoisomers, also constitutional isomers can occur. Whereas constitutional isomers can be differentiated by mass spectrometry, enantiomeric and diastereomeric differences cannot be identified easily with mass spectrometry. Five more $\mathrm{m} / \mathrm{z}$ ratios are occurring twofold. Structural proposals of selected PC TPs (different $\mathrm{m} / \mathrm{z}$ ratios) are displayed in Fig. 5. Here the stereochemical information is not displayed, because all stereocenter of MOX can be changed due to irradiation. For elucidation, associated MS/MS fragments are collated to the fragmentation pathway (given in Tables S5-S8 in ESM). As described in Fig. 3b, modifications at fragment 2, like (de-)hydration or hydroxylation can be occurring at different equivalent positions, and similar to the presented EC TPs, only one structure is displayed. The 
Table 4 Resulting PC TPs of MOX by irradiation experiments, summarized in groups by determined modification/sum formula. The accurate mass is representing the mass of the $[\mathrm{M}+$ $\mathrm{H}]^{+}$peaks of the TPs (some TPs are detected as sodium or ammonium adducts)

\begin{tabular}{cclll}
\hline Compound & Amount & calc. $m / z$ & Molecular formula & Suggested modification \\
\hline MOX & & 640.3849 & $\mathrm{C}_{37} \mathrm{H}_{54} \mathrm{NO}_{8}$ & \\
PC1 & 699.4196 & $\mathrm{C}_{37} \mathrm{H}_{60} \mathrm{~N}_{2} \mathrm{O}_{9} \mathrm{Na}$ & $+\mathrm{H}_{2} \mathrm{O},+\mathrm{Na},+\mathrm{NH}_{4}$ \\
PC2 & & 694.3567 & $\mathrm{C}_{37} \mathrm{H}_{53} \mathrm{NO}_{10} \mathrm{Na}$ & $-\mathrm{H},+2 \mathrm{x} \mathrm{O},+\mathrm{Na}$ \\
PC3 & & 685.4404 & $\mathrm{C}_{37} \mathrm{H}_{62} \mathrm{~N}_{2} \mathrm{O}_{8} \mathrm{Na}$ & $+4 \mathrm{x} \mathrm{H},+\mathrm{Na},+\mathrm{NH}_{4}$ \\
PC4 & & 681.4091 & $\mathrm{C}_{37} \mathrm{H}_{58} \mathrm{~N}_{2} \mathrm{O}_{8} \mathrm{Na}$ & $+\mathrm{Na},+\mathrm{NH}_{4}$ \\
PC5/PC6 & 2 & 680.3775 & $\mathrm{C}_{37} \mathrm{H}_{55} \mathrm{NO}_{9} \mathrm{Na}$ & $-\mathrm{H},+\mathrm{H}_{2} \mathrm{O},+\mathrm{Na}$ \\
PC7 & & 672.3748 & $\mathrm{C}_{37} \mathrm{H}_{54} \mathrm{NO}_{10}$ & $+2 \mathrm{x} \mathrm{O}$ \\
PC8-PC12 & 5 & 658.3955 & $\mathrm{C}_{37} \mathrm{H}_{56} \mathrm{NO}_{9}$ & $+\mathrm{H}_{2} \mathrm{O}$ \\
PC13-PC33 & 21 & 640.3849 & $\mathrm{C}_{37} \mathrm{H}_{54} \mathrm{NO}_{8}$ & \\
PC34 & & 636.3536 & $\mathrm{C}_{37} \mathrm{H}_{50} \mathrm{NO}_{8}$ & $-4 \mathrm{x} \mathrm{H}$ \\
PC35-PC36 & 2 & 628.3849 & $\mathrm{C}_{36} \mathrm{H}_{53} \mathrm{NO}_{8}$ & $-\mathrm{OCH}_{3},+\mathrm{H},+\mathrm{H}_{2} \mathrm{O}$ \\
PC37-PC48 & 12 & 622.3744 & $\mathrm{C}_{37} \mathrm{H}_{52} \mathrm{NO}_{7}$ & $-\mathrm{H}_{2} \mathrm{O}$ \\
PC49 & & 612.3900 & $\mathrm{C}_{36} \mathrm{H}_{54} \mathrm{NO}_{7}$ & $-\mathrm{CO}_{70}$ \\
PC50-PC51 & 2 & 608.3587 & $\mathrm{C}_{36} \mathrm{H}_{50} \mathrm{NO}_{7}$ & $-\mathrm{H},-\mathrm{OCH}$ \\
PC52 & & 593.3478 & $\mathrm{C}_{36} \mathrm{H}_{49} \mathrm{O}_{7}$ & $-2 \mathrm{x} \mathrm{H},-\mathrm{NOCH}$ \\
PC53-PC54 & 2 & 590.3482 & $\mathrm{C}_{36} \mathrm{H}_{48} \mathrm{NO}_{6}$ & $-2 \mathrm{x} \mathrm{H} \mathrm{O},-\mathrm{OCH},+\mathrm{OH}$ \\
PC55 & & 558.3345 & $\mathrm{C}_{32} \mathrm{H}_{47} \mathrm{NO}_{7}$ & $-\mathrm{C}_{5} \mathrm{H}_{7} \mathrm{O}$ \\
PC56 & & 532.3189 & $\mathrm{C}_{30} \mathrm{H}_{46} \mathrm{NO}_{7}$ & $-\mathrm{C}_{7} \mathrm{H}_{8} \mathrm{O}$ \\
PC57 & & 514.3083 & $\mathrm{C}_{30} \mathrm{H}_{44} \mathrm{NO}_{6}$ & $-\mathrm{H}_{2} \mathrm{O},-\mathrm{C}_{7} \mathrm{H}_{8} \mathrm{O}$ \\
PC58-PC59 & 2 & 510.2770 & $\mathrm{C}_{30} \mathrm{H}_{40} \mathrm{NO}_{6}$ & $-\mathrm{H}_{2} \mathrm{O},-\mathrm{C}_{7} \mathrm{H}_{12} \mathrm{O}$ \\
\hline
\end{tabular}

modifications of TPs PC7 (di-hydroxylation), PC12 (hydration), and PC38 (dehydration) are proposed at fragment 2. Modifications at the methoxime group are different, including total elimination (PC52) or the loss of methanol (PC50). The O-demethylation is occurring for PC35 (in combination with hydrogenation) and for PC54 (in combination with a dehydrogenation at fragment 2). Further modifications at fragment 1 include hydration at the nitrogen atom (PC5) or the loss of the olefincontaining chain including the oxygen (PC57 and PC59).

Analysis of the annotated TP structures reveals that most modifications are occurring at the methoxime group of MOX, and most (de-)hydration reactions are occurring at fragment 2. Similar to PC57 and PC59, two further TPs (PC55 and PC56) show losses of the olefin-containing chain, but without dehydration. As result, most PC TPs are stereoisomers, and then, hydroxylated and dehydroxylated TPs are occurring in higher amounts.

While TPs may show potential differences in ionization behavior, we assume that these differences are moderate and characterized TP signal intensities relative to MOX signal. To this end, six TPs showed a strong intensity ( $>15 \%$ of the MOX starting intensity), 11 TPs showed a moderate intensity (3-15\% of MOX), 25 TPs showed a weak intensity (1-3\% of MOX), and 18 TPs were occurring with a very weak intensity $(<1 \%$ of $\mathrm{MOX})$.

PC TPs can be assigned to three different groups (A, B, C) according to their (irradiation) time-dependent intensity pattern, illustrated in ESM Fig. S4 for selected PC TPs. Group A (ESM Fig. S4a) contains PC TPs, which reach a maximum in intensity at an irradiation time of $15 \mathrm{~min}$, followed by a sharp decrease. This is the smallest group and most associated PC TPs are MOX stereoisomers (PC13-PC33, except PC18, PC22-25). Only a low energy impact is necessary to induce stereochemical changes which can be followed by further transformation reactions. The largest group of PC TPs (B, ESM Fig. S4b, d, e) shows intensity maxima at irradiation times from 45 to $90 \mathrm{~min}$. Group B contains all PC TPs (PC1 to PC7) with higher $m / z$ than MOX (except the hydration TPs, PC8-PC12), some MOX stereoisomers, and a few PC TPs with smaller $m / z$ than MOX. Group C (ESM Fig. S4c, f) contains several PC TPs which show a constant intensity increase or which reach an intensity plateau with increasing irradiation time. Most PC TPs of group C show a lower $m / z$ than MOX (e.g., PC35 to PC52). Also, the hydration PC TPs (PC8-PC12) belong to group C. PC TPs of this group are stable (over the experimental time range) and there is no or only slow degradation visible. In conclusion, stereoisomers of MOX (group A) are generated fast by low energy impact but are then quickly transformed. PC TPs of group B are built slower and show a moderate stability. The formation of PC TPs of group $\mathrm{C}$ needs more energy and the resulting PC TPs show the highest stability. In general, PC TPs which are smaller than MOX (group C) are more stable than PC TPs which are larger than MOX (group B). 


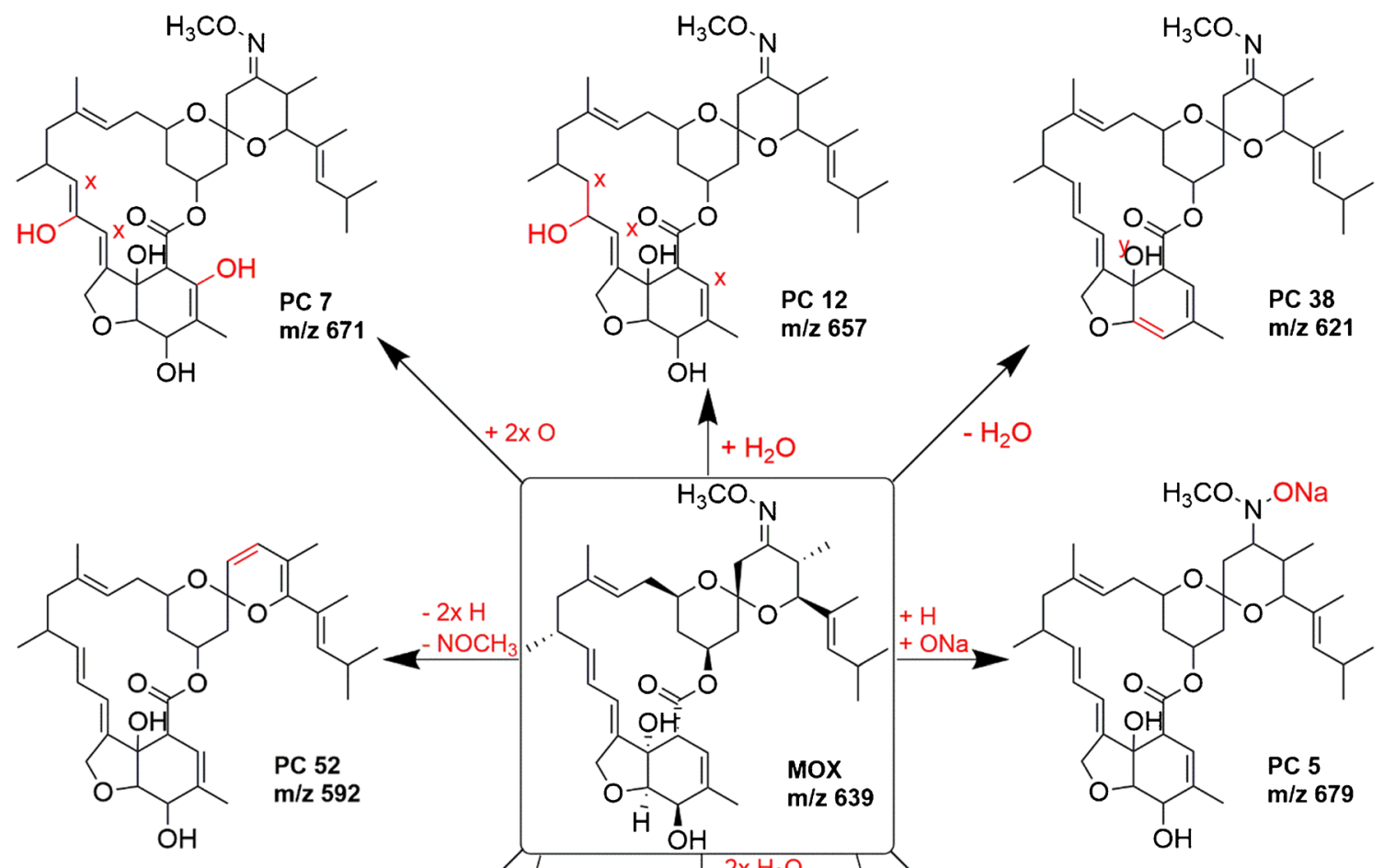

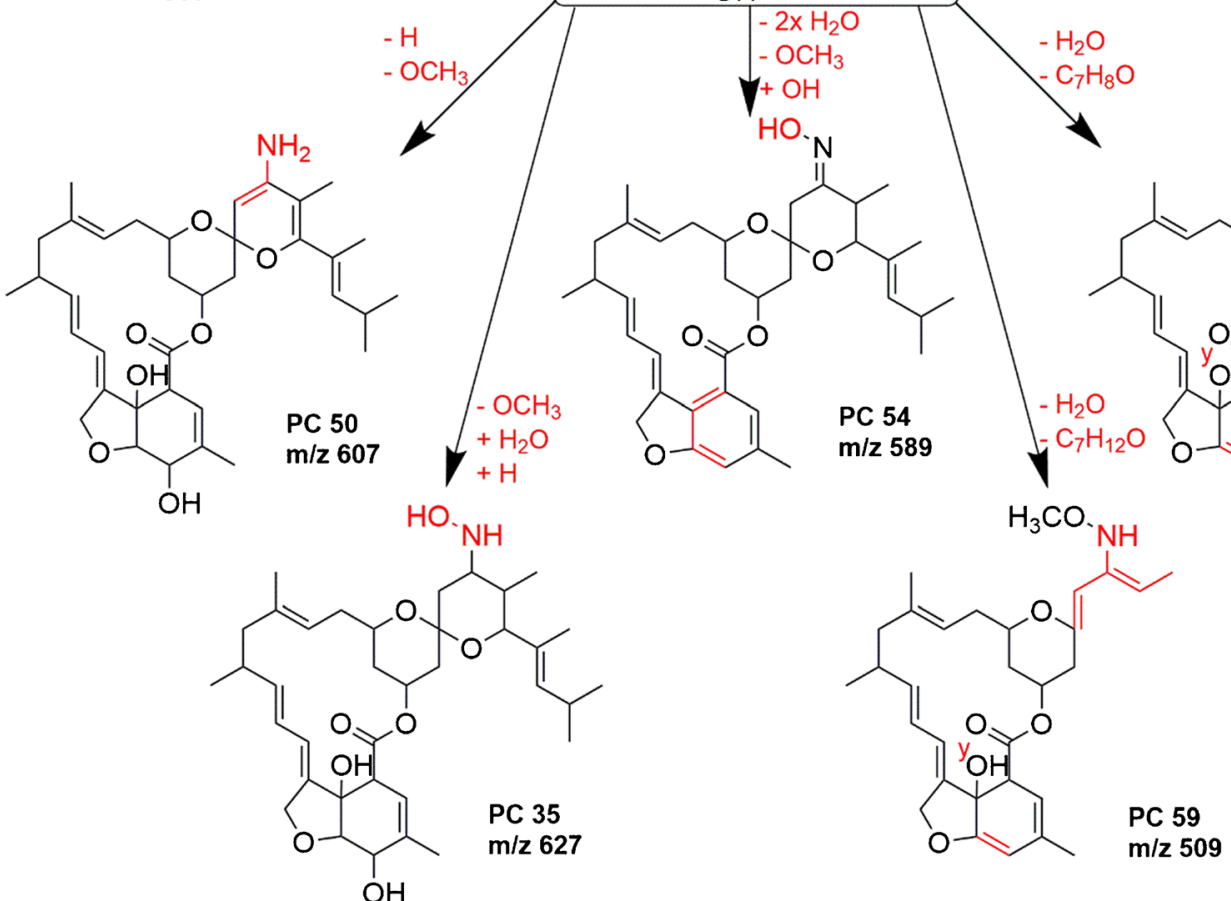

Fig. 5 Predicted structures of selected PC TPs. The x-positions marks equivalent positions of modifications at fragment 2. The y marks the second OH group for dehydration

\section{Comparison}

A broad range of different modified TPs of MOX are identified by EC and PC experiments. Furthermore, a Fenton-like reaction was tested, but no TPs of MOX are occurring (results not shown). In total, 85 unique TPs are found. It could be shown that for both experiments, the same modification reactions are occurring; these are summarized in Table 5. The modification reactions are occurring at the same regions of MOX, indicated in Fig. 3a as fragment 1 (nitrogen atom) and fragment 2 . The EC TPs showed mostly methoxy derivative formation at the methoxime group (as a follow of the electrochemical reaction of MOX with solvent methanol) and the hydration or hydroxylation were placed at fragment 2 . The PC TPs showed similar results, whereby (de-)hydration modifications are occurring at fragment 2 and most other 
Table 5 Identified modification reactions and assigned $\mathrm{EC}$ and $\mathrm{PC}$ TPs

\begin{tabular}{lcc}
\hline Modification & EC TPs & PC TPs \\
\hline Hydrogenation $(+\mathrm{H})$ & $12-14$ & 3 \\
Hydroxylation $(+\mathrm{O})$ & $1,3,4,56,8,10,12-18,20$ & 2,7 \\
Hydration $\left(+\mathrm{H}_{2} \mathrm{O}\right)$ & $1,6,7,9$ & $1,5,6,8-12,35,36$ \\
Solvent derivatives $\left(+\mathrm{OCH}_{3}\right)$ & $7,9,11-17,19,22-25$ & - \\
Stereoisomers & - & $13-33$ \\
Dehydrogenation $(-\mathrm{H})$ & $3,4,7,9,11,15,17,18,21-23,25,26$ & $5,6,34,50-52$ \\
Dehydration $\left(-\mathrm{H}_{2} \mathrm{O}\right)$ & 21,25 & $37-48,53,54,57-59$ \\
Changes methoxime group & - & $35,36,50-54$ \\
Loss of olefin-containing chain & - & $55-59$ \\
\hline
\end{tabular}

modification reactions at fragment 1 , preferably at the methoxime group. The TPs EC5 and PC7 show the same modification reaction, a di-hydroxylation. However, the retention time of both TPs is different, and MS/MS data confirmed only that both modifications are occurring at fragment 2 . Hence, EC5 and PC7 might present constitutional isomers. The known metabolites are mainly mono-hydroxylated species. The same modification reaction is found by electrochemistry, but the further structural elucidation showed that the hydroxylation is occurring at fragment 2 of MOX instead of positions of fragment 1 . Awasthi et al. [13] also found 2,3epoxy-moxidectin, a hydroxylated degradation product. However, epoxides are poorly generated by electrochemistry, which is probably why we did not detect 2,3-epoxymoxidectin. Afzal et al. [5] described three metabolites with changes in the methoxime moiety. In two metabolites, the methoxime group is replaced by a ketoxy group, one metabolite is additionally hydroxylated, and the third metabolite exhibits an O-demethylation in combination with a hydroxylation. The photochemical TPs PC35 and PC54 showed the same O-demethylation but instead of hydroxylation, other modification reactions are occurring (hydrogenation, di-dehydration). So, both methods simulate single modification reactions, which are occurring at the metabolic degradation pathway of MOX, but identical TPs are not found. The comparison of TPs found in this study with metabolites of MOX known from the literature showed no exact match; other environmental degradation products are unknown. Further environmental screenings with respect to MOX residues are necessary to better assess the laboratory results. The 85 TPs found in this study will be helpful to identify degradation products by environmental screenings, because of their rather low concentrations in organic matter. Especially the PC TPs identified for the first time could be relevant as environmental degradation products. The successful simulation of known metabolic modification reactions like hydroxylation indicates that some of the generated TPs may also be formed in natural processes (metabolic or environmental degradation).

\section{Conclusions}

This study aimed to generate TPs from MOX by electro- and photochemical transformation and elucidate their chemical structure. A total number of $26 \mathrm{EC}$ TPs was found representing 20 unique $\mathrm{m} / \mathrm{z}$ ratios and $59 \mathrm{PC}$ TPs representing 19 unique $\mathrm{m} / \mathrm{z}$ ratios. The major modification reactions of the EC-generated TPs are (de-)hydrogenation, (de-)hydration, hydroxylation, and derivative formation with solvent. Most PC TPs showed only changes in the stereochemistry (same accurate mass as MOX); additionally major reactions are hydration and dehydration. Also, several modifications are identified, mainly hydroxylation and changes at the methoxime group. Both modification reactions are received by EC or PC experiments, so observed TPs are potentially relevant metabolic or environmental degradation products. In total, we predicted chemical structures for 17 EC TPs and PC TPs, based on accurate mass and additional MS/MS data. The modifications are located at two regions of MOX, for both experiments. The identified TPs give a first insight into the degradation pathway of MOX and can serve as a basis for future toxicity or physicochemical studies. Furthermore, the results can be helpful to increase the residue analysis of MOX in real samples obtained from foodstuff, environment, or waste treatment effluents.

\section{Compliance with ethical standards}

Conflict of interest The authors declare that they have no conflict of interest.

\section{References}

1. Awasthi A, Razzak M, Al-Kassas R, Harvey J, Garg S. Analytical profile of moxidectin. Profiles Drug Subst Excip Relat Methodol. 2013;38:315-66. https://doi.org/10.1016/B978-0-12-407691-4. 00007-1. 
2. Prichard R, Menez C, Lespine A. Moxidectin and the avermectins: consanguinity but not identity. Int J Parasitol Drugs Drug Resist. 2012;2:134-53. https://doi.org/10.1016/j.ijpddr.2012.04.001.

3. Zulalian J, Stout SJ, daCunha AR, Garces T, Miller P. Absorption, tissue distribution, metabolism, and excretion of moxidectin in cattle. J Agric Food Chem. 1994;42(2):381-7. https://doi.org/10.1021/ jf00038a028.

4. Stout SJ, Dacunha AR, Wu SS, Zulalian J, Afzal J. Moxidectin characterization of cattle, sheep, and rat in-vitro and in-vivo metabolites by liquid-chromatography tandem mass-spectrometry. J Agric Food Chem. 1994;42(2):388-92. https://doi.org/10.1021/ jf00038a029.

5. Afzal J, Stout SJ, daCunha AR, Miller P. Moxidectin: absorption, tissue distribution, excretion, and biotransformation of 14C-labeled moxidectin in sheep. J Agric Food Chem. 1994;42(8):1767-73. https://doi.org/10.1021/jf00044a037.

6. Alvinerie M, Dupuy J, Eeckhoutte C, Sutra JF, Kerboeuf D. In vitro metabolism of moxidectin in Haemonchus contortus adult stages. Parasitol Res. 2001;87(9):702-4. https://doi.org/10.1007/ s004360100408.

7. Dupuy J, Escudero E, Eeckhoutte C, Sutra J, Galtier P, Alvinerie M. In vitro metabolism of $14 \mathrm{C}$-moxidectin by hepatic microsomes from various species. Vet Res Commun. 2001;25(5):345-54. https://doi.org/10.1023/A:1010686508307.

8. Afzal J, Burke AB, Batten PL, DeLay RL, Miller P. Moxidectin: metabolic fate and blood pharmacokinetics of 14C-labeled moxidectin in horses. J Agric Food Chem. 1997;45(9):3627-33. https://doi.org/10.1021/jf960981s.

9. Perez R, Cabezas I, Sutra JF, Galtier P, Alvinerie M. Faecal excretion profile of moxidectin and ivermectin after oral administration in horses. Vet J. 2001;161(1):85-92. https://doi.org/10.1053/tvjl. 2000.0521

10. Hentz SG, Fernandes MAM, Del Bianchi M, Reyes FGR, de Souza JKG, Giannotti FM, et al. Faecal excretion of moxidectin in lambs and its persistence in different environmental conditions. Small Rumin Res. 2019;174:26-33. https://doi.org/10.1016/j. smallrumres.2019.02.015

11. EMA. Moxidectin-containing veterinary medicines used in cattle, sheep and horses EMEA/V/A/116. 2017.

12. FDA. Cydectin (moxidectin $0.5 \%$ ) pour-on for cattle. Environmental Assessment Sheet no AG07187-2. 1997:United State Environment Protection Agency.

13. Awasthi A, Razzak M, Al-Kassas R, Greenwood DR, Harvey J, Garg S. Isolation and characterization of degradation products of moxidectin using LC, LTQ FT-MS, H/D exchange and NMR. Anal Bioanal Chem. 2012;404(8):2203-22. https://doi.org/10.1007/ s00216-012-6393-9.

14. Bletsou AA, Jeon J, Hollender J, Archontaki E, Thomaidis NS. Targeted and non-targeted liquid chromatography-mass spectrometric workflows for identification of transformation products of emerging pollutants in the aquatic environment. TrAC Trends Anal Chem. 2015;66:32-44. https://doi.org/10.1016/j.trac.2014.11.009.

15. ABA B, Fogg LA, Blackwell PA, Blackwell P, Kay P, Pemberton EJ, et al. Veterinary medicines in the environment. Reviews of environmental contamination and toxicology. New York: Springer New York; 2004. p. 1-91.
16. Ml F, Pérez S, Kantiani L, Barceló D. Fate and toxicity of emerging pollutants, their metabolites and transformation products in the aquatic environment. TrAC Trends Anal Chem. 2008;27(11):9911007. https://doi.org/10.1016/j.trac.2008.09.010.

17. Bartikova H, Podlipna R, Skalova L. Veterinary drugs in the environment and their toxicity to plants. Chemosphere. 2016;144:2290 301. https://doi.org/10.1016/j.chemosphere.2015.10.137.

18. Díaz-Cruz MS, López de Alda MJ, Barceló D. Environmental behavior and analysis of veterinary and human drugs in soils, sediments and sludge. TrAC Trends Anal Chem. 2003;22(6):340-51. https://doi.org/10.1016/S0165-9936(03)00603-4.

19. Agüera A, Martínez Bueno MJ, Fernández-Alba AR. New trends in the analytical determination of emerging contaminants and their transformation products in environmental waters. Environ Sci Pollut Res. 2013;20(6):3496-515. https://doi.org/10.1007/s11356013-1586-0.

20. Pico Y, Barcelo D. Transformation products of emerging contaminants in the environment and high-resolution mass spectrometry: a new horizon. Anal Bioanal Chem. 2015;407(21):6257-73. https:// doi.org/10.1007/s00216-015-8739-6.

21. Kotthoff L, Keller J, Lörchner D, Mekonnen TF, Koch M. Transformation products of organic contaminants and residuesoverview of current simulation methods. Molecules. 2019;24(4). https://doi.org/10.3390/molecules24040753.

22. Jahn S, Karst U. Electrochemistry coupled to (liquid chromatography/) mass spectrometry-current state and future perspectives. J Chromatogr A. 2012;1259:16-49. https://doi.org/10.1016/j. chroma.2012.05.066.

23. Portychova L, Schug KA. Instrumentation and applications of electrochemistry coupled to mass spectrometry for studying xenobiotic metabolism: a review. Anal Chim Acta. 2017;993:1-21. https://doi. org/10.1016/j.aca.2017.08.050.

24. Bruins AP. An overview of electrochemistry combined with mass spectrometry. TrAC Trends Anal Chem. 2015;70:14-9. https://doi. org/10.1016/j.trac.2015.02.016.

25. Hoffmann T, Hofmann D, Klumpp E, Küppers S. Electrochemistrymass spectrometry for mechanistic studies and simulation of oxidation processes in the environment. Anal Bioanal Chem. 2011;399(5):1859-68. https://doi.org/10.1007/s00216-010-4575-x.

26. Lohmann W, Karst U. Simulation of the detoxification of paracetamol using on-line electrochemistry/liquid chromatography/mass spectrometry. Anal Bioanal Chem. 2006;386(6):1701-8. https:// doi.org/10.1007/s00216-006-0801-y.

27. Fatta-Kassinos D, Vasquez MI, Kummerer K. Transformation products of pharmaceuticals in surface waters and wastewater formed during photolysis and advanced oxidation processes - degradation, elucidation of byproducts and assessment of their biological potency. Chemosphere. 2011;85(5):693-709. https://doi.org/10.1016/j. chemosphere.2011.06.082.

28. Team RC. R: a language and environment for statistical computing. 2013.

Publisher's note Springer Nature remains neutral with regard to jurisdictional claims in published maps and institutional affiliations. 